\title{
Drogas, defensa social y biopolítica ${ }^{1}$
}

\author{
Drugs, social defense and biopolitics
}

Héctor Manuel Ramírez Ríos ${ }^{2}$

Benemérita Universidad Autónoma de Puebla, México

Recepción: 28 de abril del 2021

Evaluación: 19 de julio del 2021

Aceptación: 26 de agosto del 2021

1 El presente artículo deriva del trabajo El dispositivo médico psiquiátrico y el uso de las drogas, que forma parte de los estudios doctorales realizados dentro de la línea de investigación de Filosofía práctica en la Facultad de Filosofía y Letras de la Benemérita Universidad Autónoma de Puebla con apoyo del CONACYT.

2 Licenciado y Maestro en Filosofía por la Benemérita Universidad Autónoma de Puebla.

Correo electrónico: hecmafil@gmail.com 


\title{
Resumen
}

Las drogas no fueron un tema destacado en la obra de Michel Foucault salvo ciertas menciones que pueden ser rastreadas en algunos pasajes de sus libros, artículos, cursos y entrevistas. A pesar de ello, su vasto herramental teórico sugiere algunos ejes de análisis que permiten tematizar el asunto de modo preciso. En el presente artículo se abordará el asunto del consumo de drogas en tanto que objetivo de las estrategias de poder, y sus implicaciones en la biopolítica. Después de siglos de tolerancia, a finales del siglo XIX y principios del siglo $\mathrm{XX}$, el consumo de drogas comienza a percibirse como una conducta que pone en riesgo al cuerpo individual y social. La tarea consiste en analizar algunas de las estrategias, aplicadas desde distintos focos de poder, que buscan "defender a la sociedad" de los llamados "peligros" de la droga.

Palabras clave: biopolítica, medicalización, drogas, Foucault.

\begin{abstract}
Drugs were not a prominent theme in Michel Foucault's work, except for certain mentions that can be traced in some passages of his books, articles, courses and interviews. Despite this, his vast theoretical tools suggest some axes of analysis that allow us to thematize the issue in a precise way. This article will address the issue of drug use as a target of power strategies and its implications for biopolitics. After centuries of tolerance, in the late nineteenth and early twentieth centuries, drug use began to be perceived as a behavior that endangers the individual and social body. The task is to analyze some of the strategies, applied from different focuses of power, that seek to "defend society" from the so-called "dangers" of drugs.
\end{abstract}

Keywords: biopolitics, medicalization, drugs, Foucault. 


\section{Introducción}

Antes de abordar el tema de las drogas haciendo uso del herramental teórico y conceptual propuesto por Michel Foucault, conviene llegar a una serie de acuerdos sobre la definición y el modo tradicional en que éstas han sido problematizadas en la sociedad moderna y contemporánea. En primer lugar, se trata de un fenómeno que ha estado sujeto al devenir histórico y cuya definición y usos no han sido unánimes.

En lexicografía 'droga' hace referencia a las diversas sustancias empleadas por los médicos con la finalidad de disminuir las dolencias o curar algunas enfermedades, para después referirse a los enervantes, los alucinógenos, los estupefacientes y los narcóticos que generan algún tipo de adicción, razón por la que muchas de ellas fueron prohibidas por las leyes de los países. En la cultura contemporánea, 'droga' ha llegado a referirse a aquellas substancias adictivas, y en muchos casos prohibidas por las normatividades de un determinado espacio político, así como a aquellas calificadas de legales bajo ciertas condiciones.

El diccionario de autoridades de 1726 designa con la palabra 'droga' "cualquier género de especiería, como incienso, goma, benjuí y otras varias especies aromáticas simples o compuestas. También se comprenden con esta palabra otros géneros de cosas como el maná, la xalapa, el ruibarbo, el bermellón, el cardenillo, el añil, etcétera" (Pérez Montfort, 2016, p. 27). Con el tiempo la palabra designó "sustancia mineral, vegetal o animal que se emplea en la medicina, en la industria o en las bellas artes", para posteriormente llegar a definirse como una "sustancia o preparado medicamentoso de efecto estimulante, deprimente, narcótico o alucinógeno" (RAE, 2006, p. 540).

Existe una retórica de las drogas, es decir, una serie de enunciaciones que buscan alertar sobre su naturaleza, sus usos, sus efectos y, en general, sobre el modo en que el sujeto debe comportarse frente a ellas. Jacques Derrida, en una entrevista de 1989, muy próximo al proceder argumentativo de Foucault, invita a pensar el asunto en términos histórico-discursivos. En sus palabras: "Como el de toxicomanía, el concepto de droga supone una definición instituida, institucional. Necesita una historia, una cultura, unas convenciones, evaluaciones, normas, todo un retículo de discursos entrecruzados, una retórica explícita o elíptica" (1995, p. 33). 
El régimen conceptual que se aplica a las drogas es distinto. Para ella la definición no puede ser objetiva, tal y como la otorgarían disciplinas científicas como la física o la biología. El concepto de droga no es científico; se instituye a partir de evaluaciones y criterios morales y políticos. De modo que: "(...) este concepto de droga es una norma instituida, oscura en su origen y en su historia" (p. 34). Se trata de una norma que no fluye analíticamente de un concepto científico de la toxicidad natural.

El criterio normativo que ha determinado conceptualmente a las drogas en la época contemporánea ha sido la prohibición. En la retórica de la droga, la prohibición tiene sus razones. A dicha convención le corresponde una "lógica", se justifica por una pretendida necesidad social. El prohibicionismo intenta legitimarse por la defensa de aspectos sociales tales como la salud, la seguridad, la productividad y, en general, el eficaz funcionamiento de las instituciones.

Dicho lo anterior, la prohibición busca asegurar la responsabilidad de los sujetos ante la ley. Fija además una concepción muy particular del individuo; una que pugna por su consciencia sana y normal. Así pues: “(...) no hay ley sin sujeto consciente, vigilante, normal, dueño de sus intenciones y de sus deseos. Esta prohibición, esta ley, no son entonces unos artefactos entre otros, sino la condición de posibilidad de nuestra sociedad, de un respeto por la ley en general"' (p. 34).

En el contexto del capitalismo moderno, las relaciones entre prohibicionismo y productividad se tornan patentes. El caso de Estados Unidos, país que ha exportado la mayoría de los discursos prohibicionistas al resto del mundo, nos remite a tres focos que propiciaron el desarrollo del denominado paradigma: el religioso, los movimientos migratorios y el desarrollo del capitalismo (Palomo Zamora, 2015). El acuñamiento temprano de las máximas de Benjamin Franklin (laboriosidad, frugalidad y puntualidad) para el eficaz funcionamiento del sistema económico de esa nación, condicionó las prácticas gubernamentales, direccionándolas hacia la atención del consumo de drogas, que se considera atentando contra las máximas capitalistas pronunciadas por los fundadores del país norteamericano (Basewicz Rojana, 2019).

Por lo sostenido hasta ahora, la razón que dinamiza la maquinaria prohibicionista es la protección de la sociedad, una defensa en contra de las drogas y una serie de fenómenos que acontecen en el interior del cuerpo 
social y que se refieren directamente a conductas de los individuos tales como la irresponsabilidad, el no-trabajo, la irracionalidad, la improductividad, la delincuencia, la enfermedad y los gastos sociales que le siguen. De modo que la relevancia concedida a las drogas, que se manifiesta en forma de pánico moral (Cohen, 2017), permite percibirlas como elementos disgregadores del orden moral imperante.

La tendencia prohibicionista y los movimientos con ella implicados, primero en Estados Unidos, lograron consolidar un frente contra las drogas, un auténtico dispositivo cuyas enunciaciones fueron capaces de movilizar diferentes focos de poder: agentes médicos, políticos, jurídicos, pedagógicos, religiosos y de carácter moral. El aparente deterioro social ocasionado por el alcohol y las drogas sería el argumento que los primeros prohibicionistas emplearían para explicar su incidencia delictiva en las ciudades (Escohotado, 1998).

El paradigma prohibicionista se ha extendido en la actualidad a las normatividades internacionales, gracias a los instrumentos del derecho público e internacional en forma de tratados, convenciones y acuerdos. El prohibicionismo moderno comienza a articularse como discurso en el espacio sociopolítico norteamericano a finales del siglo XIX y principios del siglo $\mathrm{XX}$, y desde entonces fue exportado al resto de los países.

Recientemente la política de corte prohibicionista se ha homogeneizado en prácticamente todo el mundo (Tenorio Tagle, 1989). Es de reconocer que el prohibicionismo se produjo con sus particularidades en cada nación, aunque en el terreno discursivo se ha asumido globalmente el enfoque patológico como justificación de dicha política. El espacio político norteamericano fue el primero en producir una ley con características paradigmáticas que sirvió de ejemplo para el resto de las políticas nacionales e internacionales, a saber, la Harrison Narcotic Act de 1914.

Continuando con el caso de los EE. UU, y tomando como punto de partida las estadísticas de Edward Brecher, a finales del siglo XIX, del 60\% al 70\% de los consumidores de opiáceos pertenecían al sexo femenino, la edad promedio de los consumidores era de 50 años, el uso se distribuía fundamentalmente entre los integrantes de la clase media y alta (Tenorio Tagle, 1989). En 1918, a cuatro años de la promulgación de la ley Harrison, los consumidores se distribuyeron en igual proporción respecto al género, al igual que aconteció 
con el resto de las variables. A partir de este momento la incidencia recaía en hombres de 30 años o menos, y los consumidores ya no se encontraban solamente en las clases acomodadas. El consumo se extendió a las clases populares, incrementándose así la demanda, que precisó de ser cubierta por los mercados ilegales. Dicha circunstancia histórico-legal configuró las diversas imágenes que se tienen respecto a los usuarios de drogas, muy próximas a la subjetividad delincuencial.

Son muchas las disciplinas que se han ocupado de estudiar el tema de las drogas desde sus diversos ángulos, como es el caso de las ciencias sociales. Sin embargo, el tema no ha sido de especial interés para la filosofía, salvo ciertas excepciones. En lo que respecta a los trabajos de Michel Foucault, el asunto de las drogas aparece como tema secundario de problemáticas más generales. En algunos casos el autor se limita a citarlas a modo de ejemplo y en otros casos forman parte de argumentos más extensos. En sus primeras obras y cursos las drogas están estrechamente relacionadas con el tema de la locura y la enfermedad mental, su empleo en el ámbito hospitalario y su decisivo papel en la experimentación científica y proto-psiquiátrica.

El filósofo apela además al uso disciplinario de la droga en el ámbito carcelario, tema que desarrollará en Vigilar y castigar. En esta misma obra, el asunto se plantea también en los términos de los ilegalismos y la delincuencia útil, que a modo de agentes fiscales administra toda una serie de prácticas ilegales, incluidas las drogas. Otro ámbito en el que aparecen las sustancias prohibidas en relación con la criminalidad y la delincuencia es en el estudio crítico que Foucault lleva a cabo sobre las políticas neoliberales y el modelo de empresa.

Los pasajes donde es abordado el tema de las drogas, así como lo manifestado en algunas de sus entrevistas y lo comentado por algunos de sus biógrafos, dejan entrever la fascinación que Foucault experimentó hacia algunas drogas como fuentes de placer y herramientas de pensamiento. Por ejemplo, según lo afirmado por James Miller, en una entrevista de 1967, el filósofo defendió el valor de ciertas drogas en virtud de su capacidad para romper con los límites culturales y facilitar que: “(...) la persona ingresara en un estado de sinrazón en el cual la experiencia de la locura queda fuera de la distinción entre lo normal y lo patológico (...)" (Miller, 1995, p. 335). Del mismo modo, su viaje al Valle de la Muerte, en 1975, así como su experiencia con drogas en California, representan un episodio importante 
en la vida de Foucault. Según lo manifestado por Simeon Wade, a pesar de sus continuos experimentos con distintas drogas, tales como el hachís y el opio, Foucault no había probado el LSD, ya que no resultaba sencillo encontrar drogas puras en París (Wade, 2019).

Como se verá, la cuestión de las drogas en Foucault aparece de modo fragmentario. Sin embargo, conceptos más elaborados como la biopolítica y la medicalización, permiten llevar a cabo un desarrollo más extenso del tema. Las políticas y legislaciones en materia de substancias adictivas son la continuación de una preocupación gubernamental que desde el siglo XVIII se ocupa de la conducta de los seres humanos, de lo que hacen con sus cuerpos, incluido lo que ingieren. Así como ha sido con el comportamiento sexual (Foucault, 2007b), a principios del siglo XX el consumo de drogas es algo que comienza a ser gestionado y administrado por las técnicas de gobierno en su vocación biopolítica.

\section{Foucault y el tema de las drogas}

Aunque las referencias al tema de las drogas en la obra de Foucault no son numerosas, su proceder investigativo y el herramental conceptual que propone permiten su abordaje filosófico. La ausencia de una obra consagrada enteramente al tema no niega el interés que el filósofo de Poitiers manifestó hacia ellas. Las referencias a dichas substancias pueden ser rastreadas en obras tan tempranas como la Historia de la locura en la época clásica (1961). En dicha obra, las alusiones al uso del opio por parte del estamento terapéutico en occidente no son escasas. Mencionando la ausencia de unidad o coherencia del pensamiento y la práctica médica durante los siglos XVII y XVIII, el autor apela a la vigencia del mito de la panacea y a la participación del opio en el mismo:

(...) la idea de la universalidad en los efectos de un remedio comienza a cambiar de sentido a finales del siglo XVII. En la querella del antimonio, se afirmaba (o negaba) todavía cierta virtud que pertenecía, por derecho propio, a un cuerpo, y que sería capaz de actuar directamente sobre el mal; en la panacea, es la naturaleza misma la que actúa y borra todo lo que pertenece a la contra-naturaleza. Pero pronto las disputas del antimonio son seguidas por las discusiones sobre el opio, que se utiliza en un gran número de afecciones, especialmente en las enfermedades de la cabeza. Whytt no tiene suficientes palabras para celebrar sus méritos y su eficacia cuando se le utiliza contra los males de los nervios (...) (Foucault, 1976, p. 462). 
Sin embargo, la condición de panacea del opio no fue unánime, tal y como lo manifiesta Foucault en la misma Historia de la locura. Otros médicos como Aumont, ven en los intoxicantes, tales como el opio, la cicuta y la mandrágora, agentes que perturban el sistema nervioso y desencadenan la sinrazón. En similar actitud, Robert James en su Diccionario de ciencias médicas, afirma que el opio es capaz de precipitar la manía por su abundancia en azufre (Foucault, 1976). Como se observa en la Historia de la locura, el opio posee una ambivalencia que será común en otras drogas. Es reconocido por sus virtudes en el tratamiento de ciertas formas de locura y enfermedades nerviosas, pero también por desencadenarlas.

Otro lugar en el que Foucault alude al tema de las drogas es en su curso sobre el Poder psiquiátrico. En la clase del 30 de enero de 1974 deja en claro que junto a las funciones del interrogatorio y la hipnosis, otro operador del proceso de medicalización, "de la realización de la locura como enfermedad", es la droga (2005). Antes del desarrollo de dicha función, el autor hace algunas menciones sobre las drogas y su uso disciplinario, que ubica por lo menos desde el siglo XVIII. Un ejemplo de lo anterior es el caso del médico Italiano Giovanni Battista Monteggia, un cirujano de las cárceles de Milán, quien sospechando la simulación de locura de un infractor: “(...) administra fuertes y repetidas dosis de opio, de modo que el delincuente se sintió tan cansado de la acción del opio que, temeroso de morir, consideró inútil seguir el fingimiento (...)" (2005, p. 319).

Seguido de su aplicación en el ámbito disciplinario, el filósofo de Poitiers habla de los usos terapéuticos de algunas drogas en el contexto de la protopsiquiatría y la psiquiatría. Durante los primeros ochenta años del siglo XIX, el opio, el nitrito de amilo, el cloroformo y el éter, fueron substancias empleadas de manera regular en los hospitales psiquiátricos. Como respaldo documental de lo anterior, Foucault remite a un texto de Morel de 1864 acerca de la eterización (2005). Sin embargo, el pasaje en donde se observa un mayor desarrollo sobre el tema es aquel que hace referencia al médico francés Moreau de Tours y su obra Du haschisch et de l'aliénation mentale de 1845, en el que el vínculo entre la droga y la locura será explícito.

Se reconoce que por lo menos desde 1840, el médico francés empleó el hachís en las instalaciones del hospital psiquiátrico de Bicètre (Escohotado, 1998). Tal y como lo relata el autor de Las flores del mal, fue el mismo Moreau 
quien hizo circular en Francia el dawamesk: "una mezcla de extracto graso, de azúcar y de diversas plantas aromáticas como vainilla, canela, pistachos, almendras, almizcle (...) bajo esta nueva forma, el hachís nada tiene de desagradable, y se puede tomar en dosis de 15, 20 y 30 gramos, bien enrollado en una hoja de pan ácimo, bien en una taza de café" (Baudelaire, 2013, p. 20). De la mano de Moreau de Tours, este comestible permitió la difusión del consumo de cannabinoides en Europa, consumo que con el tiempo daría lugar a investigaciones médicas sobre la enfermedad mental.

Para Moreau, el hachís era adecuado para arrojar luz sobre la etiología de las enfermedades nervioso-intelectuales (2019). Tenía la particularidad y el potencial de generar un estado compuesto entre el sueño y la vigilia, que conserva la conciencia de sí mismo y el sentimiento de individualidad. A través de la ingesta sistemática de hachís y las variaciones en la dosificación, el psiquiatra francés consideraba posible inducir lo que en su terminología calificaba de "desagregación" o "disociación" mental, pudiendo generar de tal forma una observación interior nunca intentada de la manía, que desde los tiempos de Philippe Pinel era considerada como la forma de locura más extendida. Siendo muy puntuales, lo que Moreau creyó descubrir mediante el consumo de hachís fue el acceso al hecho primordial que origina la locura (Foucault, 2005).

Partiendo de las propias descripciones que Moreau de Tours lleva a cabo sobre la experiencia con el hachís, Foucault señala el modo en que el alienista asimila los efectos de la droga a los procesos generales de la enfermedad mental (2005). Así pues, de entre todas las descripciones posibles de la intoxicación con hachís, Moreau privilegia las de la alienación propuestas por la psiquiatría general. Estas descripciones aluden, por ejemplo, a la disociación de ideas, al error con respecto al espacio y al tiempo, o a las llamadas convicciones delirantes.

Para Foucault, la experiencia y descripción del hachís desarrollada por Moreau consisten en una “(...) confiscación psiquiátrica de los efectos de la droga dentro del sistema de la enfermedad mental (...)” (p. 321). Desde su postura, el problema planteado por Moreau de Tours debe ser estudiado en el horizonte que ofrece una historia de la droga y no desde la historia de la enfermedad mental propuesta por la psiquiatría. Dicha asimilación de los efectos de la intoxicación con el hachís a la enfermedad mental parte de 
un supuesto, a saber, el de la "reproducción de la locura"; una invocación artificial de la enfermedad mental que experimentaría el propio psiquiatra.

En Vigilar y castigar, Foucault remite al problema de las drogas cuando estas se vinculan a los ilegalismos y a la delincuencia. Como se expone en el cuarto capítulo de la obra, la delincuencia es susceptible de emplearse directamente (2009). El autor apela al caso del siglo XIX, cuando se establece un "ilegalismo subordinado" y organizado en forma de delincuencia útil para los grupos dominantes. Un ejemplo de ello es el establecimiento de los sistemas de prostitución durante el mismo siglo XIX: “(...) en la formación de un precio del placer, en la constitución de un provecho de la sexualidad reprimida y en la recuperación de este provecho, el medio delincuencial ha sido cómplice de un puritanismo interesado (...)" (p. 325).

Dicho lo anterior, el medio delincuencial se convierte en una especie de agente fiscal ilícito sobre prácticas ilegales: "El tráfico de armas, de alcohol en los países con prohibición, o más recientemente de droga demostrarían de la misma manera este funcionamiento de la delincuencia útil (...)” (p. 325). El autor recuerda la situación que se produce alrededor de una prohibición legal, a saber, un campo de prácticas ilegales sobre las cuales se llega a ejercer control y provecho ilícito, como ocurre con las drogas. En dicho caso, y en otros, la delincuencia se constituye en un instrumento que administra y explota los ilegalismos (2009).

Durante su clase del 21 de marzo de 1979, en su curso sobre el Nacimiento de la biopolítica, Foucault aborda nuevamente el tema de las drogas y su vínculo con la delincuencia, pero ahora enmarcado en el problema del mercado y las apreciaciones de los neoliberales. Durante dicha clase, el autor analiza el modo en que los neoliberales dan cuenta de la sociedad según el modelo de la empresa, que consiste en extender los principios de la oferta y la demanda, la inversión, el costo y el beneficio a las relaciones sociales (Foucault, 2007a). Según el enfoque de esta tendencia económico-social, la generalización del modelo de la empresa funciona como principio de inteligibilidad, descifra las relaciones sociales y el comportamiento individual. Toda esa analítica sobre los problemas sociales será aplicada también al tema de la criminalidad.

Para Foucault existen casos especiales donde la criminalidad se aproxima más y mejor a las dinámicas del mercado. Tal es el caso de las drogas, que consiste en sí mismo en un fenómeno de mercado. Ello supone un análisis 
económico y una economía de la criminalidad mucho más inmediata (2007a). En este sentido, aproximadamente hasta 1970, las políticas en materia de drogas se concentran esencialmente en la reducción de la oferta:

(...) ¿Qué quiere decir reducir la oferta de droga, la oferta del crimen relacionado con la droga, la delincuencia relacionada con la droga? Quiere decir, por supuesto, reducir la cantidad de droga colocada en el mercado ¿Y qué quería decir reducir la cantidad de droga colocada en el mercado? Controlar y desmantelar las redes de refinación, y, en segundo lugar, controlar y desmantelar las redes de distribución. Ahora bien, sabemos perfectamente cuáles fueron los resultados de esa política de la década de 1960 (...) (p. 299).

Según Foucault, esta política de drogas de enfoque neoliberal trajo consigo consecuencias que agravaron el asunto en cuestión. En primer lugar, como resultado del fortalecimiento de la situación de monopolio, aumentó el precio unitario de la droga. El mercado de la droga se concentró en unos cuantos vendedores; grandes traficantes que fueron eliminando a la competencia. Como efecto del monopolio se presenta un alza de los precios al no ser respetadas las leyes del mercado. Para los consumidores esto implicó buscar y conseguir su producto bajo cualquier circunstancia y estar dispuesto a pagarlo a cualquier precio. Dicha "inelasticidad" en la demanda de drogas produjo, necesariamente, un incremento de la delincuencia (2007a).

En la entrevista de 1982, Sexo, poder y políticas de la identidad, el filósofo de Poitiers lleva a cabo una disertación que deja ver su opinión acerca de las drogas y el modo en que éstas se relacionan con el placer. En ella se lee:

(...) La posibilidad de hacer uso de nuestro cuerpo como fuente de una pluralidad de placeres reviste una enorme importancia. Si nos atenemos a la construcción tradicional del placer, comprobamos que los placeres físicos o carnales tienen su origen siempre en la bebida, en la alimentación y en el sexo. A mi juicio, ahí quiebra nuestra inteligencia del cuerpo, de los placeres. Es desesperante, por ejemplo, que no consideremos el problema de las drogas más que desde el punto de vista de la libertad o de la prohibición. Las drogas deben convertirse en un elemento cultural (...) (2015, p. 89).

Continuando con el argumento, una vez expuesta su crítica al modo tradicional de abordar el fenómeno de las drogas en términos de permisibilidad o interdicción, Foucault añade: 
(...) Debemos conocer las drogas, probar las drogas; producir buenas drogas, que induzcan placeres intensos. El puritanismo que reina en relación con las drogas, un puritanismo que obliga a estar a favor o en contra, es un craso error. Las drogas son parte integrante de nuestra cultura; igual que existe buena y mala música, hay buenas y malas drogas. E igual que sería estúpido decir que estamos contra la música, es estúpido decir que estamos contra las drogas (...) (p. 89).

Tal como se ha expuesto en el presente artículo, Michel Foucault conocía muy bien el modo en que en occidente ha sido abordada la problemática de las drogas. Aunque no lo haya hecho explícito desde lo sostenido por él mismo, las drogas han sido empleadas por las tecnologías del poder como instrumento disciplinario, pero también han sido reguladas, administradas y gestionadas, a su vez, por estrategias que se han arrogado dichas funciones. Ciertamente los vínculos del sujeto con las drogas son muy antiguos, sin embargo, la relación moderna presenta sus propias particularidades. Una de ellas es la mediación del saber y la práctica médica, que en su vocación biopolítica define los discursos válidos acerca de las drogas y determinan el modo de vincularse con las mismas.

Aunado al abordaje político, para Foucault las drogas pueden llegar a ser una vía de exploración intelectual y una importante fuente de placer que debe ser considerada en occidente. La moral tradicional y los cánones establecidos por diversos focos de poder, incluida la medicina y la psiquiatría, condicionan el modo en que se ha abordado y comprendido el fenómeno de las drogas, que según Foucault debe ser analizado desde su propia historia.

\section{Orientación biopolítica del problema}

Las prácticas de las que habla Foucault a lo largo de su obra son eminentemente políticas y deben ser entendidas desde su función gubernamental, es decir, desde su vocación por gobernar a los hombres a través de técnicas: la conducta ha sido el objetivo principal de las mismas (2006). La idea de gubernamentalidad explica la dirección que toma el arte de gobernar y manifiesta la tensión existente entre lo individual y lo colectivo, pero no explica los nuevos problemas que surgirán con el conjunto de vivientes que Foucault identifica con el nombre de población y cuya aparición ubica en el siglo XVIII (2007a). 
La biopolítica es el concepto propuesto por Foucault para identificar una forma de práctica política del todo novedosa, y que será característica de la modernidad. Se trata de la gestión a través de las técnicas de poder, de las dinámicas propias de la vida (salud, higiene, natalidad, longevidad, raza) que acontecen en el interior del cuerpo social. El filósofo emplea, por primera vez, el concepto de biopolítica en la segunda de sus conferencias sobre medicina social dictada en la Universidad de Río de Janeiro en el año de 1977. Es importante señalar, como menciona Roberto Casto, que Foucault no realizó en vida un trabajo editorial sobre el tema de la biopolítica, sin embargo, abordó el concepto en repetidas ocasiones entre los años 1974 y 1979, sin proporcionar una teoría general de la noción (Castro, 2011).

Resulta esclarecedora la relación existente entre medicina y biopolítica propuesta por Foucault en varios de sus escritos. En la misma conferencia sobre medicina social, el concepto de biopolítica aparece enmarcado en los procesos histórico-sociales que llevaron a la constitución de una medicina con vocación pública en el transcurso del siglo XVIII. En tanto que asunto público, la salud como objetivo del saber y la práctica médica, abre una serie de problemas vinculados a las relaciones del sujeto con el cuerpo. Al respecto, Foucault señala: "El control de la sociedad sobre los individuos no se realiza sólo por la conciencia o la ideología, sino también en el cuerpo y con el cuerpo. Para la sociedad capitalista, es la biopolítica lo importante, ante todo, lo biológico, lo somático, lo corporal” (1999, p. 366).

Integrada a los programas gubernamentales, la medicina atenderá en adelante cuestiones tan diversas como el cuidado de los pobres, la prevención de plagas y enfermedades contagiosas, el cuidado de los alimentos y del agua, el drenaje y limpieza de los centros urbanos, así como el uso excesivo de bebidas alcohólicas y tabaco (Rosen, 2005). El saber médico ya no estará determinado por la clínica, por todo aquello que compete a la enfermedad, los síntomas y el malestar. Desde su vocación social dirigirá sus esfuerzos a garantizar la salud de la población, promoviendo medidas higiénicas y prohibiendo conductas consideradas dañinas como el consumo excesivo de alcohol, tabaco y, hacia mediados del siglo XIX, otro tipo de drogas.

Todo este empoderamiento de la medicina, o para ser más precisos su transformación en estrategia de poder, describe una intervención creciente en la existencia de los individuos y los grupos. Esa intervención médica 
creciente puede ser designada con el nombre de medicalización, con la que se describe: "(...) el hecho de que la existencia, la conducta, el comportamiento, el cuerpo humano, se vieron englobados, a partir del siglo XVIII, en una red de medicalización cada vez más densa y extensa, red que cuanto más funciona menos cosas deja fuera de control (...)" (Foucault, 1999, p. 364). Conforme avanza el denominado proceso, mayores aspectos de la vida son codificados e intervenidos por criterios médicos. En este sentido, el consumo de drogas llegará a ser objeto de la medicalización, pues el privilegio de su enunciación y su tratamiento será concedido a la medicina y a la especialización psiquiátrica.

Las diversas cruzadas por la salud mental y moral de la humanidad (Escohotado, 1998), que comenzarán a aparecer desde mediados del siglo XIX y que se agudizarán a principios del siglo XX, cuando el consumo de drogas se extiende a las clases populares, pueden ser entendidas desde un dispositivo que comienza a configurarse: el médico-psiquiátrico. Así pues, se lleva a cabo una medicalización y psiquiatrización de los medios para alcanzar la embriaguez.

Se ha de reconocer que el empleo de drogas en la práctica médica, mucho antes del proceso de socialización del que fue objeto, ha sido una constante a lo largo de la historia universal. Tal como lo plantea Courtwright: "Durante la mayor parte de la historia de la medicina, los médicos consideraron las drogas como herramientas para alcanzar amplios efectos fisiológicos. A través de acciones tales como acelerar el pulso o regular el tránsito intestinal, suponían que ayudaban al cuerpo a recuperar su equilibrio natural (...)" (2002, p. 110).

Como es sabido, muchas de las drogas prohibidas en la actualidad fueron en un primer momento remedios legales empleados por los médicos, tal como es el caso de los opiáceos y sus derivados, la cocaína, las metanfetaminas y un largo etcétera. Las relaciones y actitudes de la medicina ante las drogas han sido muy variadas y en muchos casos paradójicas; prohíbe algunas mientras prescribe muchas otras. Esto se debe a lo móvil de los discursos sobre la salud, que como lo expresan Castel y Álvarez-Dardet (2010), nunca se limitan exclusivamente a la salud del cuerpo, sino que enuncian toda una serie de cuestiones que exceden lo estrictamente "científico" y que, a su vez, son acompañados por un contexto económico, político y social que permite legitimarlos y sustentarlos. 
Latour (2012), próximo a los planteamientos de Foucault, afirma que la ciencia médica, en su práctica, crea una política y un discurso político sobre la salud. Estos discursos terminan alcanzando invariablemente a las drogas y sus usos. La medicina no solamente enuncia cuáles son las drogas que han de ser prohibidas y cuáles han de ser prescritas, sino que también dicta los tratamientos, terapias y cuidados a los que el sujeto ha de someterse en caso de existir una relación problemática con las mismas, generalmente identificada con la adicción. Al respecto Courtwright sostiene:

Con los años, la preocupación de los médicos por este proceso originó una enorme producción de bibliografía admonitoria sobre el uso descontrolado. Por supuesto, en estos textos de advertencia el desaprensivo es el paciente, que fuma o bebe más de lo que resiste su constitución, diluye demasiada azúcar en el café, bebe demasiado café, consume demasiadas pastillas y abusa de otras sustancias que producen efectos muy benficiosos si se toman con moderación y en las circunstancias adecuadas (2002, p. 130).

Con el descubrimiento de los efectos adversos, que como ya se ha señalado comienzan a atestiguarse en el transcurso del siglo XIX y comienzos del siglo $\mathrm{XX}$, aparecen también nuevos juicios morales sobre las enfermedades que se desprenden del fenómeno del consumo, tales como la drogodependencia, la toxicomanía, el abuso de substancias, etc. En Inglaterra, a mediados del siglo XIX, “(...) a los adictos se los retrataba en los estudios de casos médicos como delincuentes incapaces de controlarse a sí mismos, cuya condena autoinfligida y autoprocurada no podía tener un final feliz en este mundo (...)" (Davenport-Hines, 2003, p. 58).

En un clima de reacción ante las inclinaciones secularizantes del mundo tecnificado, la toxicomanía comienza a identificarse con el pecado y con la "creación privada de infiernos personales" (p. 59). Como se percibe con tales aseveraciones, los juicios médicos y morales se entrelazaron con la intención de señalar un padecimiento que durante varias décadas permaneció limitado a las clases altas: "No se consideraba vergonzosa la conducta de Lady Melville ni de la duquesa de Abrantes; pero el que esos mismos hábitos se filtrasen entre los pobres era objeto de la más severa desaprobación" (p. 59). 
Tal como las investigaciones históricas lo sugieren, el consumo de medicamentos de nueva creación -ahora identificados con el nombre de drogas - fue una práctica recurrente entre la sociedad burguesa del siglo XIX, sobre todo en lo que respecta a los opiáceos, cuyo consumo suscitó casos de adicción. Con el tiempo se experimentarían una serie de problemas que trascendieron el ámbito médico. Al respecto sostiene Maugeais: “(...) estas toxicomanías dieron lugar a la descripción de nuevas entidades morbosas conforme al gran modelo anatomo-clínico, y luego, merced a su rápida difusión social, salieron del campo de la medicina para convertirse en tremenda preocupación social (...)” (2000, p. 263).

En sus inicios, la toxicomanía representó una paradoja para los médicos, ya que se trataba de un padecimiento causado por las propias prescripciones médicas, un efecto secundario del empleo de drogas para atender una determinada dolencia o enfermedad. Con la extensión del uso de drogas fuera del ámbito médico, el problema comenzó a percibirse como una afectación del espíritu, una debilidad del carácter y del ánimo que precisaba de atención especializada.

Fue así como aconteció la paulatina psiquiatrización de las diferentes toxicomanías: "La morfinomanía sirvió de modelo clínico, y se le definió sucesivamente como neurosis continua (Ball), psicosis (Laehr y Fiedler), trastorno psicosomático (Gaudry) o como reveladora de un carácter desenfrenado en un degenerado, 'borracho de morfina"' (p. 268). Según la opinión del alienista, la dependencia a substancias era descrita como una complicación que adoptaba las formas de la excitación o de la depresión, perturbaciones de las facultades afectivas, morales o del carácter.

Como se ha mostrado gracias a la recuperación histórica, el consumo de drogas, aunque lento en su caracterización etiológica, fue adoptado como objeto de una especialidad médica, en este caso, la naciente psiquiatría. La medicalización del consumo de drogas dista de concluir. Los discursos médicos en torno a las drogas han adquirido notable fuerza en la actualidad, después de la relativa relajación de las leyes persecutorias y criminalizadoras; un hecho que a menudo es interpretado como un giro filantrópico que ve en el consumidor un enfermo que precisa de ayuda especializada.

El uso de drogas considerado legítimo en medicina y ciencia representa una ambigüedad que merece atención. Se trata de un tipo de saber que sienta las 
bases teórico-científicas del paradigma prohibicionista, pero a la vez diseña nuevas drogas bajo el auspicio de la industria farmacéutica. Así pues, para autores como Peter Cohen (1990), las razones científicas que subyacen al denominado problema de las drogas y que suelen ser mostradas como modelos psicopatológicos y de dependencia, en la mayoría de los casos, reproducen la legitimación de las políticas de drogas ya expuestas, sin olvidar la posición de privilegio de los especialistas dentro del campo de investigación científica (Muñoz Robles, 2019).

Para el autor de Drugs as a Social Construct, Peter Cohen (1990), asumiendo una perspectiva histórica, la emergencia de una nueva clase profesional de médicos a finales del siglo XIX propició la clasificación de ciertas drogas como ilegales, determinándose los usos "no médicos" de tales sustancias. Es la prohibición de drogas: “(...) la que faculta al médico a practicar un monopolio que restringe la libertad de los consumidores, en este sentido la existencia del uso ilegal o no médico de drogas sería un concepto de vital importancia para las legitimaciones actuales del poder médico (...)" (Muñoz Robles, 2019, p. 24). Según dicho argumento, la definición de "uso ilegal de drogas" ayuda a la consolidación y mantenimiento de un tipo de poder en el ejercicio de la medicina y su vigencia en las políticas antidrogas.

Las investigaciones de Foucault sobre el poder médico y psiquiátrico abrieron el camino a otros pensadores que han sido conscientes de la vocación biopolítica de dichas disciplinas. No se trata de desacreditar la labor de los médicos, sino de señalar el modo en que la medicina llega a constituirse en una estrategia de gobierno y dirige su atención a objetivos antes ignorados. Con el proceso de socialización, los discursos médicos adquieren una tonalidad moral que fueron argumento suficiente para la intervención del Estado en asuntos privados como el consumo de alcohol y otras substancias. Estos discursos perdieron rigor científico, pero ganaron presencia en las decisiones políticas y jurídicas.

\section{Consideraciones finales}

Una genealogía de las drogas podría desmontar los discursos tradicionales que se han encargado de definir las relaciones legítimas con ellas, además de trazar nuevas vías para afrontar los problemas por venir. Los discursos tradicionales, como se manifestó a lo largo del presente artículo, son el resultado de diversos focos de poder tales como la religión, las instancias 
políticas y jurídicas, grupos ciudadanos, la medicina y la psiquiatría. Cada uno de esos focos de poder no deben ser entendidos como instancias aisladas e incomunicadas, pues a pesar de su heterogeneidad funcionan articuladamente como una red, hasta constituirse en lo que Foucault llama dispositivos.

La complejidad del tema de las drogas se debe a la multiplicidad de dispositivos que activa y permite operar en el interior del cuerpo social. Sin embargo, hay un dispositivo que ha gozado de mayor presencia y vigencia: el médicopsiquiátrico. Dicho dispositivo funciona en virtud de sus enunciaciones y prácticas que exceden lo estrictamente médico, entrecruzándose con ámbitos muy diversos como la política y la moral. Como se mostró a lo largo del artículo, con su socialización la medicina adquiere funciones gubernamentales; se consolida como una estrategia biopolítica que abraza variados aspectos de la existencia.

La política de drogas que se ha venido practicando desde principios del siglo XX es la expresión más visible de una serie de relaciones de saber-poder, así como de numerosos compromisos entre diversos ámbitos. El prohibicionismo ha sido la estrategia político-jurídica con mayor vigencia, pero no ha sido la única. La permisibilidad y tolerancia es otro gran discurso de la política de drogas. Con tono filantrópico, inaugura un espacio donde la coerción se pretende ausente, aunque lo que acontece es una sustitución de técnicas. La persecución policiaca es sustituida por la asistencia y por los cuidados psiquiátricos, cambiando también el estatus del consumidor de criminal a enfermo.

En términos generales, las investigaciones sobre el tema ponen el acento en las drogas ilegales. Sin embargo, el mundo contemporáneo ha coexistido con innumerables drogas legales, en muchos casos avaladas por el saber médico. En este sentido, el poder que ejerce la medicina es ambivalente, ya que prohíbe algunas drogas mientras prescribe otras. Esta aparente ambigüedad revela el alcance de sus funciones y su privilegio enunciativo, como se ha mostrado; postulados proto-científicos que no se contienen en la droga, sino que se extienden al propio sujeto consumidor y a su estatus antes referido.

Tal como lo reiteró Foucault a lo largo de sus obras, el poder se ejerce sobre los cuerpos. Uno de esos poderes ha sido la propia psiquiatría, que ha jugado un papel decisivo en materia de drogas. Sus funciones no se limitan a enunciar los efectos positivos o adversos de ciertas sustancias, sino que aunado a ello 
determina las medidas terapéuticas que han de ser tomadas cuando un sujeto entabla una relación "problemática" con las mismas. En este sentido, puede hablarse de una psiquiatrización de la droga, pero también de los sujetos. Como se mostró, Foucault identifica este fenómeno con una "confiscación psiquiátrica de la droga", confiscación que dista de concluir y que merece un estudio más amplio.

Como se ha manifestado a lo largo del presente escrito, hay una serie de discursos preconcebidos sobre las drogas. Las opiniones en favor o en contra quedan condicionadas por estos. Siguiendo los planteamientos de Foucault, las drogas deben ser repensadas más allá de los términos prohibitivos o permisivos, y con ello permitir la apertura de un espacio abierto para pensar el estatus actual del cuerpo y del placer. Por otro lado, el presente texto no busca promocionar el consumo de drogas, sino que empleando una expresión foucaultiana, invita a un adecuado "uso de los placeres" que provenga de la espontanea decisión del sujeto, como una práctica de sí en tiempos actuales.

\section{Referencias}

Basewicz Rojana, I. F. (2019). Origen y globalización del prohibicionismo. Algunos elementos para la comprensión sociohistórica del Régimen Internacional de Drogas Ilícitas. Psocial, 5 (2), pp. 34-39. https:// publicaciones.sociales.uba.ar/index.php/psicologiasocial/article/ view/3532/4293

Baudelaire, C. (2013). Los paraísos artificiales. Madrid: Valdemar.

Castiel, L. D., \& Álvarez-Dardet, C. (2010). La salud persecutoria. Los límites de la responsabilidad. Buenos Aires: Lugar Editorial.

Castro, E. (2011). Diccionario Foucault. Buenos Aires: Siglo XXI.

Cohen, P. (1990). Drugs as a social construct. [Doctoral degree, Amsterdam]. Universiteit van Amsterdam. http://www.cedro-uva.org/lib/cohen. drugs.toc.html

Cohen, S. (2017). Demonios populares y "pánicos morales": Delincuencia juvenil, subculturas, vandalismo, drogas y violencia. Barcelona: Gedisa.

Courtwright, D. (2002). Las drogas y la formación del mundo moderno. Breve historia de las sustancias adictivas. Barcelona: Paidós. 
Davenport-Hines, R. (2003). La búsqueda del olvido. Historia global de las drogas, 1500-2000 (J. A. Vitier, Trad.). México: Fondo de Cultura Económica.

Derrida, J. (1995). Retóricas de la droga. Revista Colombiana de Psicología, 4, pp. 33-44. https://revistas.unal.edu.co/index.php/psicologia/article/ view/15898

Escohotado, A. (1998). Historia general de las drogas. Madrid: Espasa Calpe.

Foucault, M. (1976). Historia de la locura en la época clásica I (J. Utrilla, Trad.). México: Fondo de Cultura Económica.

Foucault, M. (1999). Estrategias de poder (F. Álvarez y J. Varela, Trads.). Barcelona: Paidós.

Foucault, M. (2005). El poder psiquiátrico. Curso en el Collège de France (1973-1974) (H. Pons, Trad.). Buenos Aires: Fondo de Cultura Económica.

Foucault, M. (2006). Seguridad, territorio, población. Curso en el Collège de France (1977-1978) (H. Pons, Trad.). Buenos Aires: Fondo de Cultura Económica.

Foucault, M. (2007a). El nacimiento de la biopolítica. Curso en el Collège de France (1978-1979) (H. Pons, Trad.). Buenos Aires: Fondo de Cultura Económica.

Foucault, M. (2007b). Historia de la sexualidad 1: la voluntad de saber. (U. Guiñazú, Trad.). México: Siglo XXI.

Foucault, M. (2009). Vigilar y castigar. Nacimiento de la prisión (A. Garzón del Camino, Trad.). México: Siglo XXI.

Foucault, M. (2015). ¿Qué hacen los hombres juntos? (L. Pérez, Trad.). Madrid: Cinca.

Latour, B. (2012). Nunca fuimos modernos. Ensayo de antropología simétrica. Madrid: Siglo XXI.

Maugeais, P. (2000). Nueva historia de la psiquiatría (F. Gonzáles, Trad.). México: Fondo de Cultura Económica.

Miller, J. (1995). La pasión de Michel Foucault (O. Molina, Trad.). Santiago: Andres Bello. 
Moreau de Tours, J. (2019). Del hachís y de la alienación mental. Madrid: Asociación Española de Neuropsiquiatría.

Muñoz Robles, M. (2019). Contra el determinismo farmacológico: sociología de las drogas y reflexividad. Sociedad Hoy, 23, pp. 21-31. https:// revistasacademicas.udec.cl/index.php/sociedad_hoy/article/view/780

Palomo Zamora, E. (2015). Revisión histórica de la prohibición de las drogas en Estados Unidos; desde los pilgrims hasta el Partido Prohibicionista. URVIO, Revista Latinoamericana de Estudios de Seguridad, 16, pp. 102-114. https://doi.org/10.17141/urvio.16.2015.1812

Pérez Montfort, R. (2016). Tolerancia y prohibición: Aproximaciones a la historia social y cultural de las drogas en México 1840-1940. México: Debate.

RAE. (2006). Diccionario esencial de la lengua española. Madrid: Espasa Calpe.

Rosen, G. (2005). De la policía médica a la medicina social: Ensayos sobre historia de la atención a la salud (H. Sotomayor, Trad.). México: Siglo XXI.

Tenorio Tagle, F. (1989). Ideas contemporáneas en torno a las drogas y sus consecuencias en materia legislativa. México: Inacipe.

Wade, S. (2019). Foucault in California: [A True Story-Wherein the Great French Philosopher Drops Acid in the Valley of Death]. California: Heyday. 